Supporting information

\title{
Mineral Precipitation Kinetics: Assessing the Effect of Hydrostatic Pressure and Its Implication on the Nucleation Mechanism
}

\author{
Narayan Bhandari, ${ }^{\text {a* }}$ Amy T. Kan, ${ }^{\text {a }}$ Fangfu Zhang, ${ }^{\text {a }}$ Zhaoyi Dai, ${ }^{\text {a }}$ Fei Yan, ${ }^{\text {a }}$ Gedeng Ruan, ${ }^{\text {a }}$ Zhang \\ Zhang, ${ }^{a}$ Ya Liu, ${ }^{a}$ Rudi van Eldik ${ }^{b}$ and Mason B. Tomson ${ }^{\mathrm{a}}$ \\ ${ }^{a}$ Civil and Environmental Engineering, Rice University, 6100 Main Street, Houston, TX 77005 \\ ${ }^{b}$ Department of Chemistry and Pharmacy, University of Erlangen-Nuremberg, Egerlandstr. 1, \\ 91058 Erlangen, Germany; Faculty of Chemistry, Jagiellonian University, Ingardena 3, 30-060 \\ Krakow, Poland
}




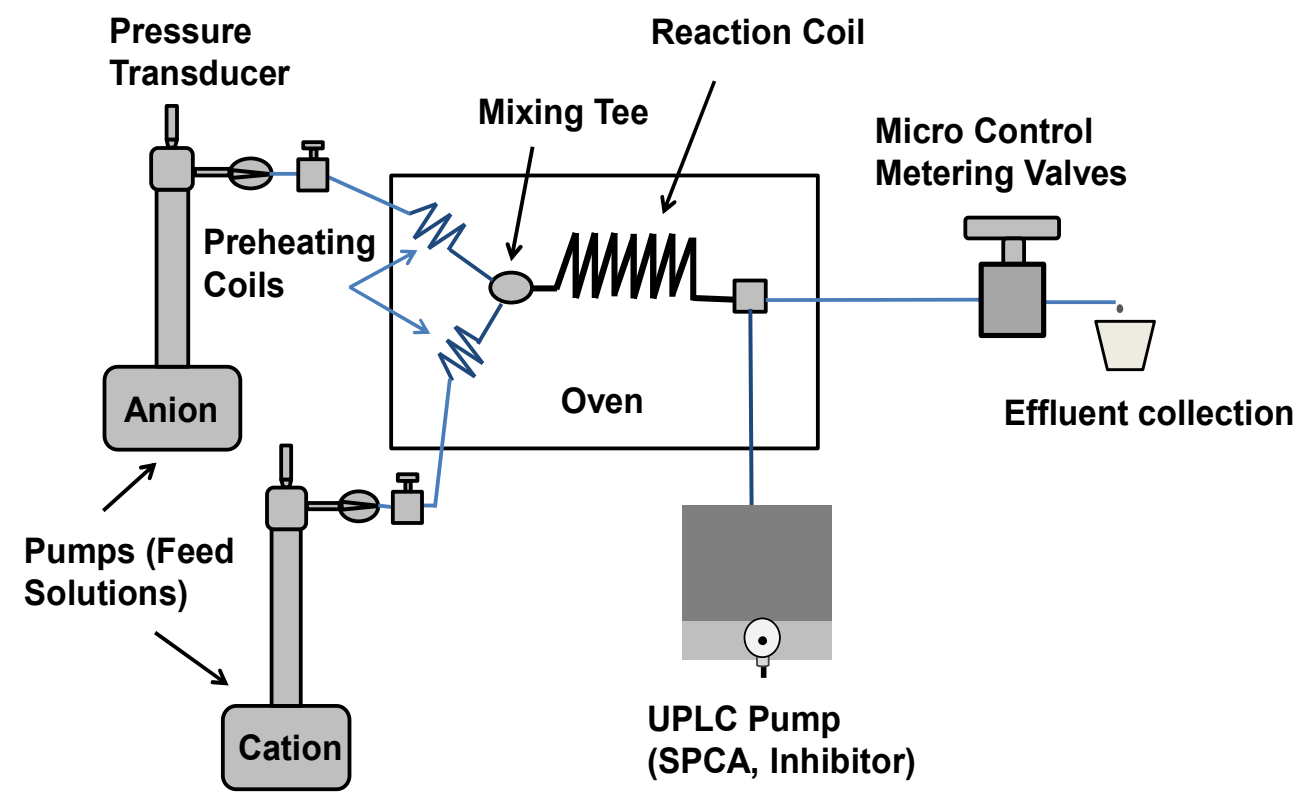

Figure $\mathbf{S}_{\mathbf{1}}$ : Schematics of dynamic flow loop apparatus.

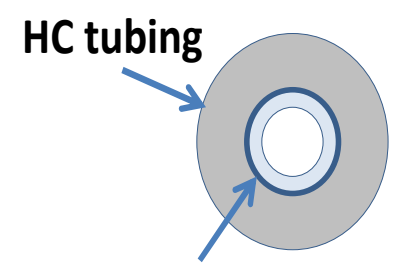

FEP tubing

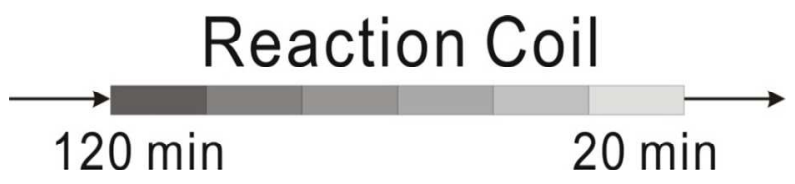

Figure $\mathbf{S}_{2}$ : Schematic of coaxial tubing (top) and scheme of sample collection (bottom) 


\section{Determination of the nucleation (induction) time}

The figure $\mathrm{S} 3$ show the time dependent concentration of the $\mathrm{Ba}^{2+}$ in reaction mixture at various time as indicated. Since the decrease of Ba ions from the reaction mixture was slow and steady even after nucleation, onset of nucleation time was calculated using intersection point of two linearly fitted lines as shown in the figure. If the measured concentrations of the cations is at least 5\% (or more) lower than of initial concentration and continue to decrees then after, 10 minutes (first measurement) was assigned as an induction time for that experimental conditions.

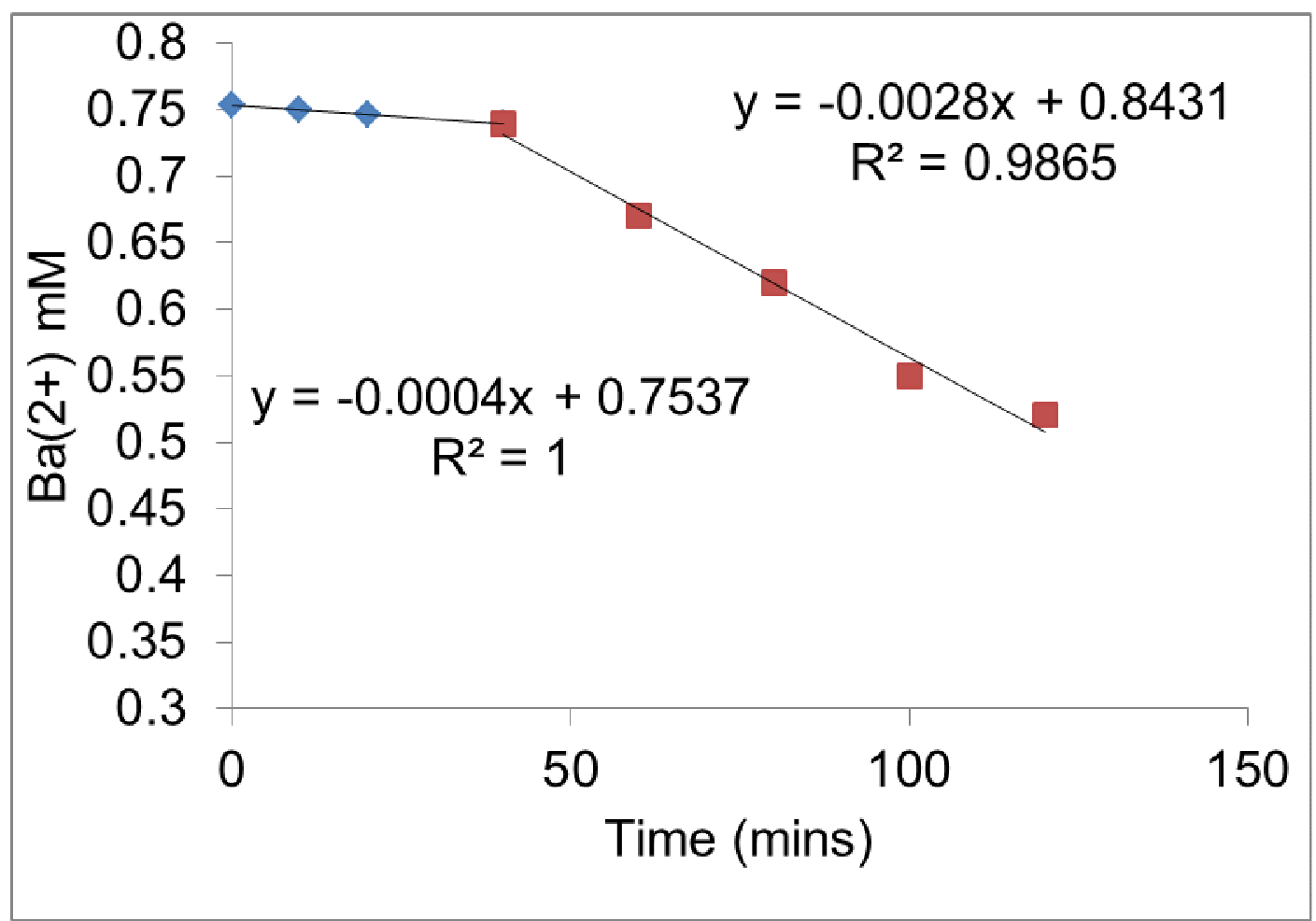

Figure $\mathbf{S}_{\mathbf{3}}$ : A plot of time dependent $\mathrm{Ba}(2+)$ concentration measured during barite nucleation study at 15,000 psia. Experimental conditions: $\mathrm{SI}_{\mathrm{BaSO} 4}=0.55, \mathrm{~T}=150{ }^{\circ} \mathrm{C}, 1 \mathrm{M} \mathrm{NaCl}, 25 \mathrm{mM}$ $\mathrm{CaCl} 2, \mathrm{pH} 6.7$ and $\mathrm{Ba}^{2+}$ to $\mathrm{SO}_{4}{ }^{2-}$ molar ratio $=1$.

\section{Experimental details and results of the barite seeded growth}

As described in detail in the ref. [1] under pug flow reaction condition the approximate precipitation rate is given by 


$$
\frac{1}{(C-C e)}-\frac{1}{\left(C_{0}-C e\right)}=k_{p p t} \cdot S . t
$$

Where,

$S=\operatorname{SSA} \cdot\left(\frac{1-\theta}{\theta}\right) \cdot \rho \cdot 10^{3}$

and, $t=\pi \cdot r^{2} \cdot L \cdot\left(\frac{\theta}{\mathrm{Q}}\right)$

$\mathrm{C}_{0}, \mathrm{C}_{\mathrm{e}}$ and $\mathrm{C}$, are concentration of the barium ions (in this case) at time 0 (initial), at equilibrium and at any contact time t. SSA is specific surface area of solid used, $\rho$ is density of solid, $r$ and L are is radius and length of column, $\theta$ is the porosity and $\mathbf{Q}$ is flow rate. Since $\mathbf{S}$ and $\mathbf{t}$ in equation (1) are physical parameters and is assumed to be similar in each case. The rate constant $\mathbf{k}$ is defined as,

$$
\mathrm{k}=\mathrm{k}_{\mathrm{ppt}} \cdot \mathrm{S} . \mathrm{t}
$$

and is estimated using the concentrations using equation (1).

\section{Estimation of entropy and enthalpy of activation of barite nucleation}

The transition state theory postulates that the reaction proceeds through formation of an "activated complex" that is in equilibrium with the reactants and the rate constant is given by [2, $3]$ :

$$
\mathrm{k}=\kappa(\mathrm{RT} / \mathrm{Nh}) \exp \left(-\Delta \mathrm{G}^{\neq} / \mathrm{RT}\right)
$$

Where $\kappa$ transmission coefficient and is generally close to unity $[2,4] . \Delta \mathrm{G}^{\neq}$is the Gibbs free energy of activation, $\mathrm{h}$ is Planck's constant, $\mathrm{R}$ is the Universal gas constant and $\mathrm{N}$ is the Avogadro's number. By using the thermodynamic relationship a relation among activation enthalpy, $\Delta \mathrm{H}^{\ddagger}$, and the activation entropy, $\Delta \mathrm{S}^{\ddagger}$ can be stabilized.

$$
\Delta \mathrm{G}^{\neq}=\Delta \mathrm{H}^{\neq}-\mathrm{T} \Delta \mathrm{S}^{\neq}
$$

Therefore,

$$
\mathrm{k}=\kappa(\mathrm{RT} / \mathrm{Nh}) \exp \left(\Delta \mathrm{S}^{\ddagger} / \mathrm{R}\right) \exp \left(-\Delta \mathrm{H}^{\ddagger} / \mathrm{RT}\right)
$$

And, 
$\ln (\mathrm{k} / \mathrm{T})=-\left(\Delta \mathrm{H}^{\neq} / \mathrm{R}\right)(1 / \mathrm{T})+\ln (\kappa \mathrm{R} / \mathrm{Nh})+\left(\Delta \mathrm{S}^{\neq} / \mathrm{R}\right)$

The equation (5) is the general form of the Eyring equation or Activated Complex Theory equation. A plot of $\ln (\mathrm{k} / \mathrm{T})$ versus $1 / \mathrm{T}$ gives a straight line with slope $-\Delta H^{\ddagger} / \mathrm{R}$ from which the Enthalpy of Activation can be derived and from the intercept $\left(\ln (\kappa R / N h)+\Delta S^{\neq} / R\right)$, Entropy of Activation can be calculated. The term $\ln (\kappa \mathrm{R} / \mathrm{Nh})$ has a known constant value 23.76 [2]. Barite nucleation experiments under constant supersaturation level at various Temperatures were conducted and nucleation times as well as experimental conditions are summarized in table 1. Figure $\mathrm{S} 4$ shows the plot of $\ln (\mathrm{k} / \mathrm{T})$ versus $1 / \mathrm{T}$. Using the slope and intercepts of $\ln (\mathrm{k} / \mathrm{T})$ versus $1 / \mathrm{T}$ plot, estimated Enthalpy of Activation $\left(\Delta \mathrm{H}^{\ddagger}\right)$ and Entropy of Activations $\left(\Delta \mathrm{S}^{\neq}\right)$of barite nucleation are $22 \pm 3 \mathrm{KJ}$ and $-209 \pm 8 \mathrm{JK}^{-1} \mathrm{~mol}^{-1}$ respectively. The large negative value of Entropy of Activation suggests an associative mechanism suggesting dehydration is not happening during transition state formation.

Table1: Estimated nucleation time of barite formation at various temperatures (SI indicates saturation index and t0 indicates nucleation time)

\begin{tabular}{|c|c|c|c|c|c|c|}
\hline $\mathrm{T}(\mathrm{K})$ & $\mathrm{SI}$ & $\mathrm{t} 0(\mathrm{~s})$ & $\mathrm{k}=1 / \mathrm{t} 0$ & $\mathrm{k} / \mathrm{T}$ & $\ln \mathrm{k} / \mathrm{T}$ & $1 / \mathrm{T}$ \\
\hline $\mathbf{2 7 7 . 1 5}$ & $\mathbf{1 . 9 9}$ & $\mathbf{2 9 0}$ & $\mathbf{0 . 0 0 3 4 4 8}$ & $\mathbf{1 . 2 4 4 1 9 E - 0 5}$ & $\mathbf{- 1 1 . 2 9 4 4}$ & $\mathbf{0 . 0 0 3 6 0 8}$ \\
\hline $\mathbf{2 9 8 . 1 5}$ & $\mathbf{1 . 9 9}$ & $\mathbf{1 1 5}$ & $\mathbf{0 . 0 0 8 6 9 6}$ & $\mathbf{2 . 9 1 6 5 4 E - 0 5}$ & $\mathbf{- 1 0 . 4 4 2 5}$ & $\mathbf{0 . 0 0 3 3 5 4}$ \\
\hline $\mathbf{3 2 3 . 1 5}$ & $\mathbf{1 . 9 9}$ & $\mathbf{7 0}$ & $\mathbf{0 . 0 1 4 2 8 6}$ & $\mathbf{4 . 4 2 0 7 7 E - 0 5}$ & $\mathbf{- 1 0 . 0 2 6 6}$ & $\mathbf{0 . 0 0 3 0 9 5}$ \\
\hline $\mathbf{3 4 3 . 2 4}$ & $\mathbf{1 . 9 9}$ & $\mathbf{3 1}$ & $\mathbf{0 . 0 3 2 2 5 8}$ & $\mathbf{9 . 3 9 8 1 1 E - 0 5}$ & $\mathbf{- 9 . 2 7 2 4 2}$ & $\mathbf{0 . 0 0 2 9 1 3}$ \\
\hline
\end{tabular}




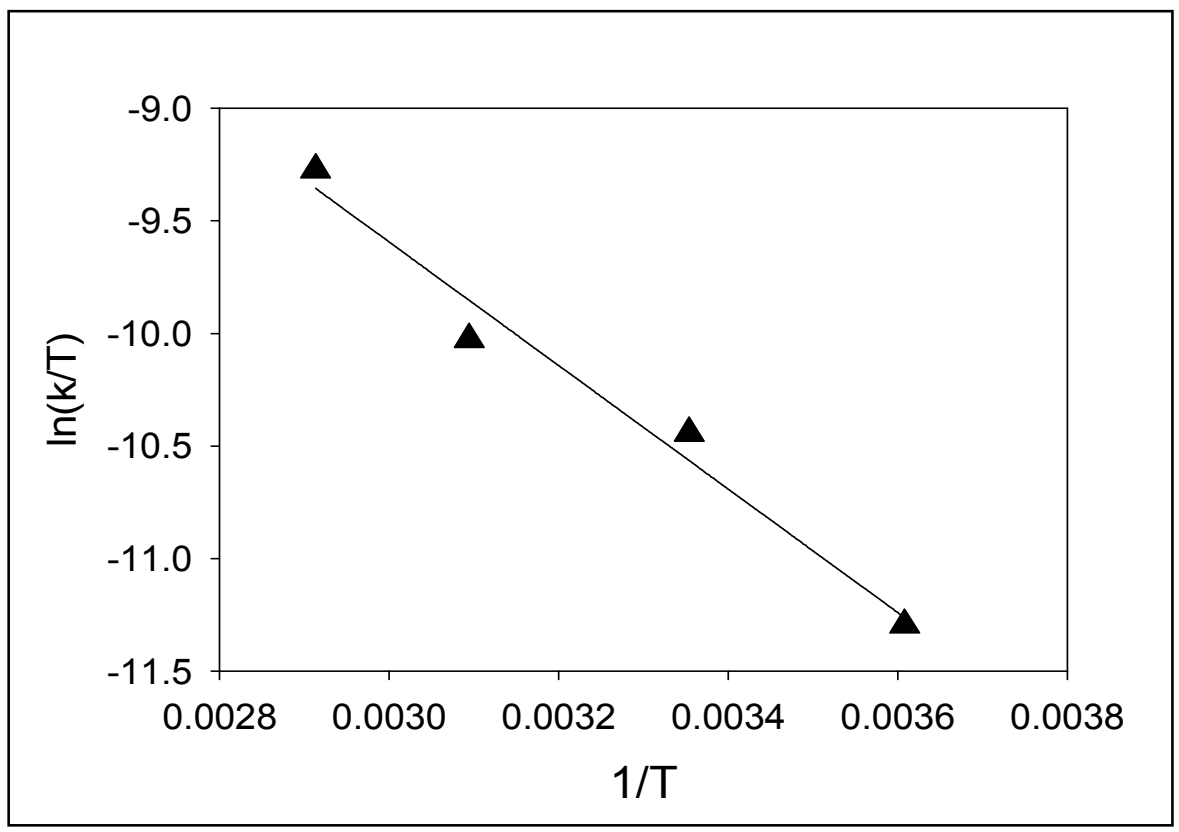

Figure S4: $\ln (\mathrm{k} / \mathrm{T})$ vs $1 / \mathrm{T}$ plot of data associated with table 1.

\section{References:}

1. Shen, D.; Fu, G.; Al-Salari, H.; Kan, A. T.; Tomson, M. B., Barite dissolution/precipitation kinetics in porous media and in the presence and absence of a common scale inhibitor. SPE J. 2009, 14, 462-471.

2. Petrou, A. L.; Terzidaki, A., Calcium carbonate and calcium sulfate precipitation, crystallization and dissolution: Evidence for the activated steps and the mechanisms from the enthalpy and entropy of activation values. Chemical Geology 2014, 381, 144-153.

3. Petrou, A. L.; Economou-Eliopoulos, M., Platinum-group mineral formation: Evidence of an interchange process from the entropy of activation values. Geochim. Cosmochim. Acta 2009, 73, (19), 5635-5645.

4. $\quad$ Espenson, J. H., Chemical Kinetics and Reaction Mechanisms. McGraw-Hill, New York: 1981 ; p 218 pp. 